Dialectologia 24 (2020), 43-57.

ISSN: 2013-2247

Received 8 February 2018.

Accepted 2 May 2018.

\title{
PHONOLOGICAL AND FUNCTIONAL ANALYSIS OF DIMINUTIVE MARKER -WAA IN MAGAHI
}

\author{
Lata ATREYA \& Sweta SINHA \\ Indian Institute of Technology Patna * \\ lata.atreya@gmail.com / apna1982@gmail.com
}

\begin{abstract}
Diminutives are universal linguistic features generally affixed to a root and modified to convey a slighter degree of its root meaning along with a range of possible meanings that get attached to them like conveying intimacy or endearment, smallness of the object, inferiority in quality, gender largely feminine and so on. Languages have diminutives to convey all or some of the meanings listed above. In many languages, formation of diminutives by adding suffixes is a productive process.

In Magahi (an Indo Aryan language) too diminutives are suffixes that are attached to the root modifying its meaning to serve a range of grammatical functions. Of all the diminutives in Magahi -waa seems to be the most frequent and dynamic because of its allomorphs. Interestingly, the investigation of the underlying phonological processes helps one to understand the accommodating and the dynamic nature of this suffix with regards to its grammaticalization.
\end{abstract}

\section{Keywords}

diminutives, Indo- Aryan, Magahi phonology, allomorphs

* Department of Humanities and Social Sciences, Indian Institute of Technology Patna, Bihta, Patna801106, Bihar, India. 


\section{ANÁLISIS FONOLÓGICO Y FUNCIONAL DEL MARCADOR DIMINUTIVO -WAA EN MAGAHI}

\section{Resumen}

Los diminutivos son características lingüísticas universales generalmente afijadas a una raíz y modificadas para transmitir un grado más leve de su significado junto con una gama de posibles significados que se les atribuyen, como transmitir intimidad o cariño, pequeñez del objeto, inferioridad de calidad, uso de género en gran medida femenino y así sucesivamente. Las lenguas tienen diminutivos para transmitir todos o algunos de los significados enumerados anteriormente. En muchas, la formación de diminutivos al agregar sufijos es un proceso productivo.

En magahi (una lengua indoaria) también los diminutivos son sufijos que se unen a la raíz modificando su significado para cumplir una serie de funciones gramaticales. De todos los diminutivos en Magahi -waa parece ser el más frecuente y dinámico debido a sus alomorfos. Curiosamente, la investigación de los procesos fonológicos subyacentes ayuda a comprender la naturaleza acomodaticia y dinámica de este sufijo con respecto a su gramaticalización.

\section{Palabras clave}

diminutivos, indoaria, fonología magahi, alomorfos

\section{Introduction}

Magahi is an Indo-Aryan language (Grierson 1903) developed from Eastern Magadhi Apbhransa (Chatterji 1926) belonging to the Magadhan subfamily. The other modern representatives of the Magadhan subfamily are Maithili and Bhojpuri (Comrie 2001). It is spoken primarily in Eastern India mainly in the states of Bihar and Jharkhand and in some districts of Orissa and West Bengal. This paper is an attempt to investigate the phonological processes involved in the formation of Magahi diminutives and the functional analysis of the diminutive marker /-waa/ and its allomorphs. Jurafsky (1996) attempted to identify universal tendencies in the meanings of the so- called diminutive in order to explain the wide range in its connotations, including smallness of size, femaleness and affection among others. Jurafsky argued that the concepts "small" and "child" lie at the heart of the semantics of the diminutive cross- linguistically. In certain linguistic investigations, diminution has been routinely offered cogent interpretive 
accounts relating to politeness in informal discourse (Sifianou 1992a, 1992b; Badarneh 2010) and gender issues (Makri- Tsilipakao 2003).

Even the actual examples used in Sifianou (1992a) seem to allow for additional directions as well, namely in terms of 'grammaticalization' and subjectification in the context of certain constructions motivated by Greek "cultural ethos" (cf. Brown \& Levinson 1987) which is the main focus of his research. The 'grammaticalization' of certain words creates new forms, introduces categories that did not use to receive linguistic expressions, [and] transforms the overall system (Meillet 1912/ 1926: 133). Campbell \& Janda (2001: 95) note that grammaticalization is seen as typically involving a "concurrent 'weakening' of both meaning and phonetic form" and as represented by the overall cline lexical> syntactic $>$ morphological. That is to say a lexical item becomes a form word with syntactic function and may end up as a morphological marker, an affix.

The diminutive marker /waa/ is a marker on Noun in Magahi and has five allomorphs as highlighted in 1-5 below. They are [waa], [aa], [yaa], [yaaN] and [maa]. Allomorphs are variants of a morpheme which occur in different phonological environments or context when compared with an underlying form. Following are illustrations from Magahi, indicating various environments for the occurrence of the morpheme /waa/ and its allomorphs.

$\begin{array}{lll}\text { Magahi } & \text { Gloss } & \text { Diminutive } \\ \text { 1. raajaa } & \text { 'king' } & \text { : raj-waa } \\ \text { 2. go:bar } & \text { 'cowdung' } & \text { : gobar-aa } \\ \text { 3. aadami } & \text { 'human being' } & \text { : adami-yaa } \\ \text { 4. raani } & \text { 'queen' } & \text { : rani-yaaN } \\ \text { 5. ratan } & \text { 'Ratan' } & \text { : ratan-maa }\end{array}$

Like Magahi, in Dutch (Hoek 2009) too one finds different variants of the diminutive suffix. The codified standard language of Dutch has five allomorphs (-tye, -etye, -ye, -pye and -kye) that are distributed according to phonetic and prosodic criteria. Among these 
five allomorphs -tye is the base form and the variants have arisen due to place assimilation.

In the present paper the discussion will be on the phonological environment of occurrence of diminutive suffix /waa/ and its allomorphs in Magahi. The discussion will also focus on the underlying form of these allomorphs being /waa/ and how it has various realizations as [aa], [yaa], [yaaN] and [maa]. Various phonological processes seem to be involved in these realizations. [aa] is formed from /waa/ by elision process. Similarly, [yaa] involves palatalization, [yaaN] involves nasal assimilation and [maa] involves neutralization. Palatalization is a common phenomenon for diminutive formation in Magahi and Kashmiri (Bhat n.d.). Along with phonological analysis, there is a short functional analysis of diminutive marker /waa/. On the function of the diminutive maker /waa/ and its allomorphs, Alok (2014) writes that these have different linguistic and psychological meanings such as specificity, definiteness, intimacy, irritation, anger, disrespect and affection that can be resolved only in a discourse.

In this paper we talk about functions of the diminutive marker /waa/ and its allomorphs as that of being an endearment and derogation particle and also as a specificity marker. These are also indicative of number and gender. Section 1 introduces the paper. Section 2 discusses the phonological environment of the morpheme /waa/ and its allomorphs. Section 3 tries to establish the allomorph /waa/ as the underlying form and section 4 talks about the functional analysis of the diminutive marker /waa/ and its allomorphs. Section 5 summarizes the paper.

Before proceeding into the details of these phonological processes, let us have a look at the basic syllable pattern and stress pattern existing in Magahi. Syllable is a phonological unit containing an obligatory nucleus preceded by an optional consonant onset and followed by an optional consonant coda. Nucleus has a special status as the only obligatory constituent. The special status of the nucleus also shows up in its role as the optimal tone or stress bearing element. The primitive syllable inventories are $\{\mathrm{CV}, \mathrm{VC}$, V, CVC\} (Kenstowicz 1994). Magahi avoids consonant clusters at the onset and at the coda position (Sinha 2014). The various syllable structures in Magahi are V, CV, VC, CVC and CV:C. The main stress in Magahi falls on the penultimate syllable (Sinha 2014). 


\section{Phonology behind diminutive marker /waa/ and its allomorphs in Magahi}

\subsection{The occurrence of /waa/}

The allomorph /waa/ gets suffixed to a lexeme under three phonological conditions. These phonological conditions are discussed here in the following paragraphs.

The lexeme ending in -aa preceded by CC. In this case, -aa of mother lexeme remains as it is (in emphatic speech) or is reduced to short vowel $-a$, in the diminutive form of the lexeme. The following 6-9 is an illustration of the same.

$\begin{array}{lll}\text { Mother Lexeme } & \text { Gloss } & \text { Diminutive form } \\ \text { 6. riks-aa } & \text { 'rickshaw' } & \text { riks-aa-waa / riks-a-waa } \\ \text { 7. laRk-aa } & \text { 'boy' } & \text { laRk-aa-waa /laRk-a-waa } \\ \text { 8. cilk-aa } & \text { 'child' } & \text { cilk-aa-waa /cilk-a-waa } \\ \text { 9. TaTk-aa } & \text { 'fresh' } & \text { TaTk-aa-waa / TaTk-a-waa }\end{array}$

In the above examples, the long vowel/-aa/ in the mother lexeme is preceded by a CC sequence. The CC sequence in example 6 is ' $k s^{\prime}$. In 7 it is ' $R k^{\prime}$ '. In 8 it is ' $I k^{\prime}$. In 9 it is ' $T k^{\prime}$ '. There is a syllable break in the CC cluster. The first $\mathrm{C}$ is counted as coda of the first syllable and the second $\mathrm{C}$ is counted as onset of the second syllable. This syllable break is because of the property of Magahi language by which it avoids consonant cluster at onset and coda position (Sinha 2018). Following are syllabic structure along with stress pattern on the lexemes illustrated in the above examples 6-9.

$\begin{array}{ll}\text { Mother lexeme } & \text { Diminutive form } \\ \text { ri'k.s-aa } & \text { rik.s-'aa / a-waa } \\ \text { la'R.k-aa } & \text { laR.k-'aa / a-waa } \\ \text { ci'l.k-aa } & \text { cil.k-'aa / a-waa } \\ \text { Ta'T.k-aa } & \text { TaT.k-'aa / a-waa }\end{array}$


The general stress pattern in Magahi is that on the penultimate syllable. From the list above we find the stress pattern on mother lexemes and their diminutive form. Mother lexeme has stress on the first syllable which shifts to medial syllable of the diminutive form. Both the syllables having stress are positioned penultimately.

Following 10-19 is a second list of lexemes which take /waa/ as diminutive marker. All these lexemes originally end in open front vowel /aa/. Mother lexeme has long vowel in the penultimate syllable, which also bears stress. Addition of diminutive marker /waa/ leads to elision of vowel /aa/ of mother lexeme with the shortening of vowel in the penultimate syllable of the mother lexeme. In this case, the number of syllables in the mother lexeme and the lexeme formed with diminutive marker /waa/ remain same. So is the penultimate syllable which bears stress. However, vowel shortening in the penultimate syllables in the diminutive forms happens. Penultimate stress occurring in Magahi lexemes is again the reason behind no insertion of vowel /a/ in diminutive forms in these cases.

\begin{tabular}{|c|c|c|}
\hline Mother lexeme & Gloss & Diminutive form \\
\hline 10. ra'a. j-aa & 'king' & ra'j. -waa \\
\hline 11. kare'. j-aa & 'heart' & kare'j. -waa \\
\hline 12. cu'. h-aa & 'rat' & cu'h. -waa \\
\hline 13. ri:'. t-aa & 'Rita' & ri:'t. -waa \\
\hline 14. lai'. k-aa & 'boy' & lai'k. -waa \\
\hline 15. be'. T-aa & 'son' & be'T. -waa \\
\hline 16. gho'. R-aa & 'horse' & gho'R. -waa \\
\hline 17. khaTo'. I-aa & 'bed' & khaTo'l. -waa \\
\hline 18. cako' . I-aa & 'roti maker' & cako'l. -waa \\
\hline 19. su'g. g-aa & 'parrot' & su'g. -waa \\
\hline
\end{tabular}

In the cases above we find that the final $\mathrm{C}$ of the mother lexeme counts as onset of the final syllable, whereas in the diminutive form it gets counted as coda of the penultimate syllable. This is so because of the fact that Magahi disallows CC cluster thus 
avoiding cluster of $\mathrm{C}$ of the ult syllable of the mother lexeme with the $\mathrm{C}$ (which is $\mathrm{w}$ ) of the diminutive form.

There is yet another group of lexemes that take /waa/ as diminutive marker. These lexemes do not end in vowel /aa/. These lexemes are listed as under 20-24. These lexemes which are originally stressed at the ult syllable when suffixed with /waa/ the stress shifts to the penultimate syllable of the diminutive form. This leads to the vowel in the antepenultimate syllable (of diminutive form) getting shortened. However, in the second case, 25-27, there is no apparent change in the stress position. The original lexemes as well as the diminutives both have primary stresses on the penultimate syllable.

\begin{tabular}{|c|c|c|}
\hline Mother lexeme & Gloss & Diminutive form \\
\hline 20. b-a'a-gh & 'tiger' & b-a'-gh. -waa \\
\hline 21. mi. j-a'a-j & 'mood' & mi.j-a'-j. -waa \\
\hline 22. si. y-a'a-r & 'jackal' & si.y-a'-r. -waa \\
\hline 23. puu. w-a'a-r & 'hay' & puu.-a'-r. -waa \\
\hline 24. ka. p-a'a-r & 'head' & ka. p-a'-r. -waa \\
\hline Mother lexeme & Gloss & Diminutive form \\
\hline 25. n-a'-T & 'dramatist' & n-a'-T-waa \\
\hline 26. kho'.D-a-r & 'hollow' & kho. D-a'-r. -waa \\
\hline 27. ja'n. t-a-r & 'amulet' & 'jan. t-a'-r. -waa \\
\hline
\end{tabular}

\subsection{The occurrence of /aa/}

The allomorph /aa/ is carved out of morpheme /waa/ by the elision process. Since the allomorph is /aa/, it will be naturally attached to lexemes not ending in /aa/. The occurrence of allomorph /-aa/ as a diminutive marker happens under three phonological environments which are discussed below as $a, b$ and $c$.

a) /-aa/ as a diminutive marker gets attached to lexemes, when the $V$ preceding the final $C$ is long and the length of the vowel remains as it is when the lexeme is getting 
converted into the diminutive form. In the diminutive form, the final $\mathrm{C}$ of the mother lexeme, counts itself as the onset of the final syllable. Here the final syllable is formed by addition of suffix /aa/ resulting into diminutive form. Stress is again on the penultimate syllable of the diminutive form. Following list, 28-33, illustrates this case.

$\begin{array}{lll}\text { Mother lexeme } & \text { Gloss } & \text { Diminutive form } \\ \text { 28. } \text { c-a'u-r } & \text { 'rice' } & \text { c-a'u-. r-aa } \\ \text { 29. } \text { D-o':-m } & \text { 'shudra' } & \text { D-o':.-m-aa } \\ \text { 30. go': b-a:-r } & \text { 'cowdung' } & \text { go:.b-a':.-r-aa } \\ \text { 31. } \text { b }^{\text {h-a'a-t }} & \text { 'cooked rice' } & \text { b'-a'a-. t-aa } \\ \text { 32. } \text { p-a'a-n } & \text { 'beetle leaf' } & \text { p-a'a-. n-aa } \\ \text { 33. da'a. n-a:-v } & \text { 'demon' } & \text { daa:. n-a':. -v-aa }\end{array}$

b) /-aa/ as a diminutive marker gets attached to the lexeme, when the end consonant is bilabial plosive; the end consonant gets geminated with the shortening of the vowel preceding it. The following (34-35) illustrate this.

$\begin{array}{lll}\text { Mother lexeme } & \text { Gloss } & \text { Diminutive form } \\ \text { 34. } \text { b-a'a-p } & \text { 'father' } & \text { b-a'-p.p-aa } \\ \text { 35. } \text { ki.t-aa-b } & \text { 'book' } & \text { ki. t-a'-b.b-aa }\end{array}$

c) When the lexeme ends with vowel /-u:/ or /-u/, /-aa/ as a diminutive marker gets attached to the lexeme. Examples 36-37 demonstrate this.

\begin{tabular}{|c|c|c|}
\hline Mother lexeme & Gloss & Diminutive form \\
\hline 36. bu'.ta. r-u: & 'child' & bu. ta'r-u. -aa \\
\hline a'l. I-u: & 'potato' & al. I-u'. -aa \\
\hline
\end{tabular}




\subsection{The occurrence of /-yaa/}

a) The allomorph /-yaa/ attaches to a lexeme ending in bilabial plosive (/p/, /b/), or dental plosive (/t/, /d/). In such cases, /i/ epenthesis happens before addition of /-yaa/ suffix. /i/ epenthesis is followed by shortening of vowel in the preceding syllable (38-39). There are cases where vowel in the preceding syllable is already short (40-41), so, shortening doesn't happen in such cases. In these cases, /i/ epenthesis breaks the consonant cluster $C$ (plosive). $C(y$-palatal). Moreover, penultimate stress on diminutive form (38-41), makes /i/ extrametrical. We will look in case (b) for suffixing of /yaa/ as diminutive marker, /i/ is already present in mother lexeme. While syllabification of such cases, /i/ undergoes syncope i.e. deletion. Again, syncope is supported by penultimate stress on the diminutive form. Following is the list, illustrating suffixation of /yaa/ in diminutive form with /i/ epenthesis.

\begin{tabular}{|c|c|c|}
\hline Mother lexeme & Gloss & Diminutive form \\
\hline 38. n-a'a-d & 'cattle feeding trough' & $n-a^{\prime}-d-\iota$ i ı-yaa \\
\hline 39. ki. t-a'a-b & 'book' & ki. t-a'-b. - i i -yaa \\
\hline 40. a'u. r-a-t & 'lady' & au. r-a'-t.-( i )-yaa \\
\hline 41. $g-a^{\prime}-p$ & 'gossip' & g-a'-p. - - i > -yaa \\
\hline
\end{tabular}

b) /-yaa/ gets attached to the lexeme which already ends with /i/ or /i:/. While diminutive formation, the vowel in the preceding syllable represented by /i/ or /i:/, should be short. If in the mother lexeme, the vowel in the preceding syllable represented by /i/ or /i:/ is long, it gets shortened in the process of getting converted into diminutive form. So, lexeme undergoing diminutive formation with the addition of diminutive marker /-yaa/ there must be /i/ at the boundary between the mother lexeme and the diminutive marker. The penultimate syllable in relation with /i/ must have a short vowel. In this case while syllabification /i/ undergoes syncope. This is illustrated in list 42-53. 


\begin{tabular}{|c|c|c|}
\hline Mother lexeme & Gloss & Diminutive form \\
\hline 42. a'a. d-a-mi: & 'man' & a.d-a'-m. < i >-yaa \\
\hline 43. n-a'a. -ti: & 'grandson' & n-a'-t. < i >-yaa \\
\hline 44. bi. j-u:'. -li: & 'current' & bi. j-u'-I. < i >-yaa \\
\hline 45. b-u:'.-dhi: & 'intelligence' & b-u'-dh. ( i >-yaa \\
\hline 46. g-u'-D. Di: & 'Guddi' & g-u'-D. < i >-yaа \\
\hline 47. bh-a'u. -ji: & 'sister-in-law' & bh-э'j. < i >-yaa \\
\hline 48. si. p-a'a. -hi: & 'solder' & sip-a'-h. < i >-yaa \\
\hline 49. h-a'a. -thi: & 'elephant' & h-a-th. < i >-yaa \\
\hline 50. kiit-aa-b & 'book' & kit-a'-b. -८ i >-yaa \\
\hline 51. ke. t-a'a-ri: & 'sugarcane' & ke. t-a'-r. < i >-yaa \\
\hline 52. b-a'a-l. ti: & 'bucket' & b-a'-l. -t < i >-yaa \\
\hline 53. n-a'a-p & 'measurement' & n-a'-p. < i >-yaa \\
\hline
\end{tabular}

\subsection{The occurrence of /yaaN/}

The suffix /-yaaN/ gets attached to lexeme ending in /n/, /ni/ or /ni:/. Such lexemes are usually feminine in gender. If the lexeme does not have /i/ or /i:/ at the end, the diminutive formation inserts /i/ between the boundary of mother lexeme and /-yaaN/ suffix. Vowel shortening happens in the mother lexeme undergoing diminutive formation with /-yaaN/ suffixation just as it happens with /-yaa/ suffixation. Again, even in this case (as in section 2.3) while syllabification of the diminutive form, /i/ undergoes syncope. The data 54-59 illustrate this.

\begin{tabular}{|c|c|c|}
\hline Mother lexeme & Gloss & Diminutive form \\
\hline 54. s-o':-.ni & 'Soni' & s-o'-n. < i >-yaaN \\
\hline 55. r-a'a-. ni & 'queen' & r-a'-n. < i >-yaaN \\
\hline 56. ca. m-a'i-. ni & 'midwife' & ca. m-æ'-n. < i >-yaaN \\
\hline 57. che. k-u'-. ni & 'small stick' & che.k-u'-n. < i >-yaaN \\
\hline 58. na'a. $t-\iota \mathrm{i}\rangle-n$ & 'granddaughter' & na.t-i'-n- i 〉-yaaN \\
\hline 59. si.y-a'a. -rin & 'jackal' & si.y-a'-r-n.-〈 i 〉-yaaN \\
\hline
\end{tabular}


In examples 58 and $59, / \mathrm{i} /$ epenthesis is happening as the mother lexeme do not end in /i/. Presence of /i/ before /-yaa/ or /-yaaN/ is because of spread of [-round] property of the vowel/i/ to the semi vowel /y/. In other words, /i/ and /y/ are both [-round], while /w/ is [+round]. Thus, presence of /i/ either by originality or by epenthesis before the phoneme /-yaa/ or /-yaaN/ is justified. However, while syllabification of the diminutive form, /i/ is undergoing syncope.

We find from the examples in list 54-59, that nasalization at the end of the mother lexeme is getting spread to the diminutive marker, thus diminutive marker /-yaa/ is becoming /yaaN/.

\subsection{The occurrence of /maa/}

The allomorph /-maa/ as a diminutive marker gets attached to the lexemes ending with /n/, /na/ or /naa/. These lexemes are of masculine or neuter gender. The data below (60-64) illustrate this.

$\begin{array}{lll}\text { Mother lexeme } & \text { Gloss } & \text { Diminutive form } \\ \text { 60. } \text { ra. ta'-n } & \text { 'Ratan' } & \text { ra. ta'n. -maa } \\ \text { 61. } \text { ra. ma'-n } & \text { 'Raman' } & \text { ra.ma'n. -maa } \\ \text { 62. } \text { i:'.n. ja-n } & \text { 'engine' } & \text { i:n. ja'n. -maa } \\ \text { 63. sa'p. -naa } & \text { 'dream' } & \text { sa. p-a'-n. -maa } \\ \text { 64. } \text { pa'T. -naa } & \text { Patna City } & \text { pa. T-a'-n. -maa }\end{array}$

We find in examples 63 and 64, that when the lexeme ends in /-aa/, the morpheme /-aa/ is getting elision and in syllable preceding the diminutive marker, /-a/ epenthesis happens to break the consonant cluster. In other words, /-a/ epenthesis occurs between the sequence CC preceding the syllable represented by diminutive marker /-maa/. In these cases, the nasal feature of the morpheme $/ n /$ is getting spread to the original diminutive marker /-waa/, which due to neutralization, gets transformed to /-maa/. Looking into stress pattern in this case, somewhere it is on ult and some where it is on 
penultimate syllable on the mother lexeme. In the diminutive form, the stress is on penultimate one.

\section{3. /waa/ as the underlying form}

Looking into the data (1-64), we can conclude the following about the environment of the morpheme /waa/ and its allomorphs [aa], [yaa], [yaaN] and [maa]:

-/yaa/ occurs in /i/ ending words,

-/yaaN/ occurs in words having nasal ending and belongs to feminine gender,

-/maa/ occurs in words having nasal ending and is of masculine or neuter gender,

-/aa/ and /waa/ have similar environment except when words end in vowel.

We have /waa/ occurring in words ending in vowel /aa/, whereas allomorph /aa/ occurring in words ending in / $\mathrm{u}$ / or /uu/ vowel. While /aa/ has limited application, /waa/ occurs freely with the words ending in consonants. Thus, we conclude that /waa/ is the underlying form as the diminutive marker morpheme or it is the unmarked form.

\section{Functional analysis of diminutive marker /waa/ in Magahi}

The diminutive marker /waa/ has various roles to play in Magahi. It acts as endearment or derogatory particle. It is specificity marker. It is also indicative of number and gender.

\subsection{Function of endearment and derogation}

Depending on the connotation of the word to which the diminutive marker /waa/ or its allomorphs are attached, it adds to the lexeme the semantics of endearment (affection) or derogation. For example, maa is a lexeme having connotation of love, so the diminutive form /maiyaa/ is used as a lexeme of endearment. As an illustration of connotation of derogation, is the lexeme baap. So, the form bappaa is used derogatively (Atreya 2017). 


\subsection{Specificity Marker}

The lexeme having diminutive marker /waa/ or its allomorphs as suffix, indicates a specific noun (Atreya 2017, Alok 2014), which has already been introduced in the conversation. For example, when we say 'tota-waa uD gelai' (the parrot flew), the lexeme 'tota-waa' indicates a specific parrot.

\subsection{Number}

The diminutive marker /waa/ has /wan/ as plural form. Similarly, /yaa/ has /yan/ and /aa/ has /an/ as their plural form. For example, 'laRkaa-waa' (boy) has plural form 'laRka-wan' (boys). laRki-yaa (girl) has plural form 'laRki-yaN' (girls). Kita-b-baa (book) has plural form kitaab-b-an (books).

\subsection{Gender}

The diminutive marker /yaaN/ gets suffixed to lexeme ending in / $/$ or / ni/ and feminine in gender. The diminutive marker /maa/ gets attached to lexeme with nasal ending which are of masculine or neuter gender. An illustration of first occurrence is 'raani' (queen) with its diminutive form 'rani-yaaN'. An illustration of second occurrence is 'ratan' (name of a boy), with its diminutive form 'ratan-maa'.

\section{Conclusions}

The suffix /waa/ is a diminutive marker on nouns in Magahi. It has various allomorphs such as /aa/, /yaaa/, /yaaN/ and /maa/. It has allomorphs such as /wan/, /an/ and /yan/ which are plural marker. We discussed in the paper that /waa/ is the underlying form. The diminutive marker has various functions such as endearment and derogatory suffix. It is also specificity marker. There are allophones such as /yaaN/ and /maa/ whose 
application depends on gender of the mother lexeme. Thus, diminutive marker /waa/ is highly functional in Magahi. The phonological processes associated with /waa/ and its allomorphs are elision, palatalization, nasal assimilation and neutralization.

\section{References}

ALOK, D. (2014) "The Morpho- Syntax of Nominal particle -wa”, Indian Linguistics, 75 (3-4), 39-44. ATREYA, Lata (2017) "Diminutive and augmentative system in Magahi", International Journal of Linguistics, 9(4), 47-62.

BAdARNeH, Muhammad A. (2010) "The pragmatics of Diminutives in Colloquial Jordanian Arabic", Journal of Pragmatics, 42(1), 153-167.

BHAT, Rajnath (n.d.) "Diminutives and augmentatives: A note on Hindi and Kashmiri", BHU-India.

<www.academia.edu/6307419/DIMINUTIVES_and_AUGMENTATIVES_A_Note_on_Hindi_and_Kas hmiri>

Brown, Penelope \& Stephen C. LeVInson (1987) Politeness: Some Universals in Language Usage, Cambridge: Cambridge University Press.

CAMPBELL, Lyle \& Richard JANDA (2001) “Introduction: Conceptions of Grammaticalization and Their Problems", Language Sciences, 23, 95-112.

CHATTERJ, S. K. (1926) The Origin and Development of the Bengali Language, Calcutta: Calcutta University Press.

COMRIE, B. (2001) "Languages of the world", in Mark Aronoff \& Janie Rees-Miller (eds.), The Handbook of Linguistics, Oxford: Blackwell, 19-42.

Grierson, G.A. (1903) Linguistic Survey of India. vol. V, part 2, Calcutta: Office of the Superintendent of Government Printing, India.

HOEK, Michel van der (2009) "The Dutch diminutive suffix and palatalization in Medieval Dutch", Zeitschrift für Dialektologie und Linguistik, 76(1), 1-13.

JURAFSKY, D. (1996) “Universal Tendencies in the Semantics of the Diminutive”, Language, 72(3), 533-578.

KenSTOWICZ, Michael (1994) Phonology in Generative Grammar, Oxford: Blackwell Publishing.

MAKRI- TSILIPAOU, Marianthi (2003) “Greek Diminutive Use Problematized: Gender, Culture and Common Sense", Discourse and Society, 14(6), 699-726. 
Dialectologia 24 (2020), 43-57.

ISSN: 2013-2247

MeIllet, Antoine (1912/1926) "L'evolution des forms grammaticales", Scientia (Revista di Scienza) 12(26), 384-400. [Reprinted in his Linguistique historique at linguistique generale, 130-148, Paris: Champion: 1926 ( $2^{\text {nd }}$, enlarged ed.: $1^{\text {st }}$ ed. 1921; reprinted by Klincksieck, Paris, 1951.] SIFIANOU, Maria (1992a) "The Use of Diminutive in Expressing Politeness: Modern Greek versus English", Journal of Pragmatics, 17, 155-173.

SIFIANOU, Maria (1992b) Politeness Phenomena in England and Greece: A Cross-Cultural Perspective, Oxford: Clarendon Press.

SINHA, Sweta (2014) The prosody of Stress and Rhythm in Magahi, PhD Thesis, New Delhi: Jawaharlal Nehru University.

SINHA, Sweta (2018) Magahi Prosody, New Delhi: Bahri Publications. 